\title{
Prospective study of job stress and risk of infections in Swedish adults
}

\author{
Francesca Ghilotti (ㄷ) 1,2 Torbjörn Åkerstedt 다, 3,4 Rino Bellocco, 2,5 \\ Hans-Olov Adami, ${ }^{5,6}$ Ylva Trolle Lagerros ${ }^{1,7}$
}

- Additional material is published online only. To view please visit the journal online (http://dx.doi.org/10.1136/ oemed-2020-106489).

'Department of Medicine, Clinical Epidemiology Unit, Karolinska Institutet, Stockholm, Sweden

${ }^{2}$ Department of Statistics and Quantitative Methods, University of Milan-Bicocca, Milano, Italy

${ }^{3}$ Department of Clinical Neuroscience, Karolinska Institutet, Stockholm, Sweden

${ }^{4}$ Stress Research Institute, Department of Psychology, Stockholm University, Stockholm, Sweden ${ }^{5}$ Department of Medical Epidemiology and Biostatistics, Karolinska Institutet, Stockholm, Sweden

${ }^{6}$ Clinical Effectiveness Research Group, Institute of Health, University of Oslo, Oslo, Norway ${ }^{7}$ Obesity Center, Academic Specialist Center, Stockholm Health Services, Stockholm, Sweden

\section{Correspondence to} Dr Francesca Ghilotti, Department of Medicine Solna, Karolinska Institute, Stockholm 171 76, Sweden: francesca.ghilotti@ki.se

Received 18 February 2020 Revised 22 May 2020 Accepted 2 June 2020 Published Online First 23 June 2020

\section{Check for updates}

(C) Author(s) (or their employer(s)) 2020. No commercial re-use. See rights and permissions. Published by BMJ.

To cite: Ghilotti F,

Åkerstedt T, Bellocco R,

et al. Occup Environ Med

2020;77:681-690.

\section{ABSTRACT}

Objectives Psychological stress may influence both susceptibility and severity of infections. Although workrelated stress is a widespread concern among many employees, few studies have been conducted with the focus on work stressors and infections. We therefore aimed to investigate this association in a prospective cohort study.

Methods Our study included 25029 employed individuals who filled-out a questionnaire in September 1997 and were followed through record linkages until retirement or December 2016. Work stress was assessed at baseline using a Swedish version of the DemandControl Questionnaire, whereas hospital contacts related to infections were identified from the National Patient Register. We fitted extensions of the standard Cox model to account for recurrent infections.

Results In total, we observed 8257 infections. Individuals in the third tertile of job demand had a 13\% higher hazard of infections ( $\mathrm{HR}=1.13 ; 95 \% \mathrm{Cl}=1.03$ to 1.24) compared with individuals in the first tertile, specifically an increased incidence of upper respiratory tract infections ( $H R=1.15 ; 95 \% \mathrm{Cl}=1.00$ to 1.33$)$ and urinary tract infections $(\mathrm{HR}=1.31 ; 95 \% \mathrm{Cl}=1.09$ to 1.57$)$ was found. Employees with the highest job control (third tertile) had no lower risk of infections than individuals in the lowest tertile $(H R=1.02 ; 95 \% \mathrm{Cl}=0.92$ to 1.13$)$. When combining the demand and control dimensions into job strain scale, no association between high job strain and infections was observed $(H R=1.08 ; 95 \%$ $\mathrm{Cl}=0.97$ to 1.21 ).

Conclusion High job demand, but not low job control, is associated with an increased occurrence of infections. No difference was observed in workers with high strain jobs compared with those with low strain jobs.

\section{INTRODUCTION}

Psychological stress is known to be related to various health conditions, in particular cardiovascular diseases and mental disorders. ${ }^{1-4}$ Recently, the possible relationship between psychological stress and infectious outcomes became a field of interest. ${ }^{5}$ In particular, stress seems to play a role both in susceptibility and in severity of infections, ${ }^{6}$ presumably by reducing resistance to infectious agents. Negative emotions induced by stress might suppress the immune system via increased production of cortisol or effects on the central nervous system, which, if continuously activated, might dysregulate the immune function through the release of catecholamines into lymphoid organs. ${ }^{8}$ An effect
Key messages

What is already known about this subject?

- Few studies have investigated the relationship between work-related stress and risk of infections, and all of them are cross-sectional, rely on self-reported outcomes or are conducted on small sample sizes.

- Some studies found a higher risk for common cold in individuals with high job demands or low job control, but findings are inconsistent.

\section{What are the new findings?}

- In this study, workers with high job demands have a higher risk of upper respiratory tract infections and urinary tract infections compared with those with low job demands.

- The decision latitude at work does not seem to be associated with infections leading to hospitalisation.

- No difference in infection occurrence was observed in workers with high strain jobs compared with those with low strain jobs.

How might this impact on policy or clinical practice in the foreseeable future?

- Our study provides evidence that stressful jobs are unlikely to substantially increase the risk of infections requiring medical attention. However, if interventions have to be taken in order to diminish the risk of infections, our results suggest to focus on the demand dimension, instead of the decision latitude. Nevertheless, future studies are needed in order to confirm our findings.

of stress on infections might also be mediated by unhealthy behavioural changes such as smoking, alcohol drinking and not eating or sleeping properly, which in turn suppress the immune system activity. ${ }^{9}$

According to a recent survey, one-third of Europeans work to tight deadlines and at high speed, factors leading to job-related stress. ${ }^{10}$ Though the cost of work-related stress to society is not well established, a recent systematic review estimated it to range between US\$221 million (Australia) and US $\$ 187$ billion (USA), with Sweden placed in the middle (US\$703 million). ${ }^{11}$

Nevertheless, few have investigated work stressors and risk of infections. All studies we are aware of 
either dealt with self-reported upper respiratory tract infections or measured surrogate endpoints. Additionally, most of these studies were cross-sectional, which hampers causal conclusions. For example, reduced natural killer cell activity among individuals with high work load or job strain was observed in Japanese nurses, ${ }^{12}$ in Italian male university employees ${ }^{13}$ and among men working in factories and construction yards. ${ }^{14}$ A negative association was also found between perception of job control and plasma fibrinogen concentration. ${ }^{15}$ Studies on occupational stress, high demand, low control and inadequate social support as risk factors for respiratory infections have chiefly relied on self-reported outcomes and inconsistently reported higher risk for common cold. ${ }^{16-18}$

The lack of large prospective studies on occupational stress and a wide spectrum of infections objectively measured prompted us to investigate this association using a cohort of about 25000 employed individuals followed-up up to 19 years with record linkages.

\section{METHODS}

\section{Study population}

In September 1997, in occasion of a fund-raising event organised by the Swedish Cancer Society throughout Sweden, the Swedish National March Cohort was established. Participants to the event were asked to fill out a questionnaire concerning lifestyle and medical history; the final number of subjects recruited into the cohort was $43865 .{ }^{19}$

Inclusion criteria for this prospective study were being aged 18 years or older and employed at the time of the enrolment. Retired participants and those with missing data on at least half of the items used for the demand and/or control score were excluded. The final cohort consisted of 25029 participants.

\section{Exposure assessment}

Job strain was measured by the Swedish version of the DemandControl Questionnaire (DCQ). ${ }^{20}{ }^{21}$ Demands at work were assessed by four questions (work very fast, work very hard, too much demand and not enough time), while the decision latitude was computed from six questions (learn new things, non-repetitive work, creativity required, high skill level, decide on how you do your work and decide on what you do in your work). Responses were rated on a four-point scale ranging from $1=$ Seldom/Never to $4=$ Always/Almost always. Mean scores for job demand and job control items were calculated for each individual. Tertiles of the two job dimensions scores were then obtained. As in previous research, ${ }^{22}$ we used the quadrant approach to define job strain and to derive the following combined categories: high strain (high demands/low control), passive job (low demands/ low control), active job (high demands/high control) and low strain (low demands/high control). High demands were defined as having a job demand score greater than the median, whereas a job control score below the median was considered as having low control.

\section{Follow-up and outcomes}

Participants were followed from 1 October 1997 until the date of retirement, death, emigration or end of the follow-up on 31 December 2016, whichever occurred first. Through the use of the unique personal identification number, provided by participants at baseline, the cohort was linked to the Total Population Register and the Migration Register to obtain dates of death, relocation and emigration, the National Patient Register to obtain information on medical data and the Longitudinal Integrated
Database for health insurance and Labour Market Studies (LISA) database to obtain data on employment, retirement and income. All community-acquired infections requiring healthcare contact (either private or public, but not primary care) and occurring during follow-up were considered as events of interest. Infections were grouped as upper respiratory tract infections, lower respiratory tract infections, gastrointestinal tract infections, skin and subcutaneous tissue infections, urinary tract infections and other infections. Infections were identified through the International Classification of Diseases, Tenth Revision (ICD-10) from the Swedish National Inpatient and Outpatient registers (only the primary diagnosis code was used). ${ }^{23}$ Detailed ICD-10 codes are reported in online supplementary table S1.

\section{Statistical analyses}

Baseline characteristics of the study cohort are reported over job strain categories in table 1 and over job demand and job control tertiles in online supplementary table S2. Categorical variables are summarised using absolute numbers and percentages, whereas continuous variables using the median and IQR.

Due to the recurrent nature of the outcome of interest, we fitted survival models for multiple failure time data to investigate the association between job demands, job control and job strain with the occurrence of infections. When events occur more than once, failure times are correlated within subject and methods accounting for lack of independence are needed. ${ }^{24}$ In this study, we fitted extensions of the standard Cox model using robust SEs to account for correlation. Specifically, we used the Andersen-Gill model ${ }^{25}$ in the analyses when multiple infections were of different types, and the Prentice, Williams and Peterson Total Time (PWP) model ${ }^{26}$ when recurrent infections were of the same type. These models allowed us to estimate HRs and 95\% CIs. To obtain reliable estimates and avoid small risk sets ${ }^{27}$ infections beyond the seventh occurrence were ignored. All models were fitted with age as the underlying timescale. Cox proportional hazards assumption was tested using Schoenfeld residuals. Stratified Cox models for recurrent events were implemented for predictors who did not fulfil the assumption of proportional hazards (sex).

Based on a priori assumptions on the relationships between confounders, intermediate variables, exposure and outcome, we drew a directed acyclic graph (DAG) to select the minimal set of variables needed to adjust the models for ${ }^{28}$ (online supplementary figure S1). Three different sets of analyses were conducted. (a) First, models were adjusted for age and sex; (b) then, we included education (compulsory school, high-school, university), physical activity (sex-specific tertiles of total physical activity MET*hours/day, ${ }^{29}$ shift work (daytime; shiftwork), disposable income (categorised in quartiles) and Charlson's comorbidity index $(0 ; 1 ; \geq 2)^{30}$ as suggested by the DAG; (c) finally, statistical analyses were also refined by adding the potential intermediate variables: body mass index (BMI), smoking status (non-smokers; former smokers; current smokers), sleep duration $(\leq 6 ; 7$; $\geq 8$ hours) and alcohol consumption (none; low; medium/ high). As main analysis, we conducted a complete case analysis excluding participants with missing values on covariates. The percentage of missing values across the potential confounders varied between $0 \%$ (age, sex, Charlson's comorbidity index) and $7 \%$ (smoking status).

Subgroup analyses were performed by occupational titles (white and blue collars). White-collar and blue-collar employees were defined using the Swedish Standard Classification of Occupations (SSYK single-digit level). White-collar workers (SSYK: 
Table 1 Baseline characteristics of employed individuals $(n=25029)$ in the Swedish National March Cohort, stratified by job strain

\begin{tabular}{|c|c|c|c|c|}
\hline & Low strain job & Passive job & Active job & High strain job \\
\hline Number of participants & 5882 & 7402 & 6334 & 5411 \\
\hline \multicolumn{5}{|l|}{ Sex } \\
\hline Female & $3737(64 \%)$ & $5200(70 \%)$ & $4085(64 \%)$ & $3827(71 \%)$ \\
\hline Male & $2145(36 \%)$ & $2202(30 \%)$ & $2249(36 \%)$ & $1584(29 \%)$ \\
\hline Age (years) & $46.3(35.8-53.9)$ & $46.5(34.8-54.4)$ & $47.2(38.1-53.6)$ & $46.6(34.4-54.0)$ \\
\hline Body mass index $\left(\mathrm{kg} / \mathrm{m}^{2}\right)$ & $23.9(22.0-26.3)$ & $23.8(22.0-26.2)$ & $24.2(22.2-26.4)$ & $23.9(22.0-26.3)$ \\
\hline Missing (n) & 207 & 290 & 228 & 250 \\
\hline \multicolumn{5}{|l|}{ Education } \\
\hline Compulsory school & $628(11 \%)$ & $1563(21 \%)$ & $563(9 \%)$ & $1098(20 \%)$ \\
\hline High school & $2130(36 \%)$ & $4209(57 \%)$ & $1978(31 \%)$ & $3034(56 \%)$ \\
\hline University/PhD & $3118(53 \%)$ & $1623(22 \%)$ & $3785(60 \%)$ & $1274(24 \%)$ \\
\hline Missing (n) & 6 & 7 & 8 & 5 \\
\hline \multicolumn{5}{|l|}{ Smoking } \\
\hline Non-smoker & $3443(62 \%)$ & $4391(63 \%)$ & $3631(62 \%)$ & $3114(62 \%)$ \\
\hline Former smoker & $1643(30 \%)$ & $1941(28 \%)$ & $1722(29 \%)$ & $1357(27 \%)$ \\
\hline Current smoker & $444(8 \%)$ & $591(9 \%)$ & $522(9 \%)$ & $537(11 \%)$ \\
\hline Missing (n) & 352 & 479 & 459 & 403 \\
\hline \multicolumn{5}{|l|}{ Alcohol consumption } \\
\hline None & $452(8 \%)$ & $710(10 \%)$ & $469(7 \%)$ & $479(9 \%)$ \\
\hline Low & $2865(49 \%)$ & $3879(52 \%)$ & $2807(45 \%)$ & $2894(54 \%)$ \\
\hline Medium/high & $2552(43 \%)$ & $2783(38 \%)$ & $3035(48 \%)$ & $2016(37 \%)$ \\
\hline Missing (n) & 13 & 30 & 23 & 22 \\
\hline \multicolumn{5}{|l|}{ Charlson's comorbidity index } \\
\hline 0 & $5519(94 \%)$ & $6906(93 \%)$ & $5952(94 \%)$ & $5044(93 \%)$ \\
\hline 1 & $159(3 \%)$ & $200(3 \%)$ & $158(2 \%)$ & $149(3 \%)$ \\
\hline$\geq 2$ & $204(3 \%)$ & $296(4 \%)$ & $224(4 \%)$ & $218(4 \%)$ \\
\hline Missing (n) & 0 & 0 & 0 & 0 \\
\hline \multicolumn{5}{|l|}{ Physical activity (MET*hours/day)* } \\
\hline Low $(<32(\mathrm{~F}) ;<35(\mathrm{M}))$ & $2053(35 \%)$ & $2647(36 \%)$ & $2053(32 \%)$ & $1587(29 \%)$ \\
\hline Medium (32 to $39(\mathrm{~F}) ; 35$ to $46(\mathrm{M})$ ) & $2093(36 \%)$ & $2385(32 \%)$ & $2223(35 \%)$ & $1638(30 \%)$ \\
\hline $\operatorname{High}(>39(\mathrm{~F}) ;>46(\mathrm{M}))$ & $1735(29 \%)$ & $2365(32 \%)$ & $2056(33 \%)$ & $2182(41 \%)$ \\
\hline Missing (n) & 1 & 5 & 2 & 4 \\
\hline \multicolumn{5}{|l|}{ Shift work } \\
\hline Daytime & $5006(87 \%)$ & $5726(79 \%)$ & $5277(85 \%)$ & $3902(74 \%)$ \\
\hline Shiftwork & $717(13 \%)$ & $1477(21 \%)$ & $944(15 \%)$ & $1364(26 \%)$ \\
\hline Missing (n) & 159 & 199 & 113 & 145 \\
\hline \multicolumn{5}{|l|}{ Sleep duration } \\
\hline$\leq 6$ hours & $1516(26 \%)$ & $2196(30 \%)$ & $2137(34 \%)$ & $2027(38 \%)$ \\
\hline 7 hours & 2917 (50\%) & $3395(47 \%)$ & $2942(47 \%)$ & $2252(42 \%)$ \\
\hline$\geq 8$ hours & $1401(24 \%)$ & $1709(23 \%)$ & $1180(19 \%)$ & $1046(20 \%)$ \\
\hline Missing (n) & 48 & 102 & 75 & 86 \\
\hline \multicolumn{5}{|l|}{ Sleep quality } \\
\hline Medium/good & $3597(61 \%)$ & $3985(54 \%)$ & $3406(54 \%)$ & $2542(47 \%)$ \\
\hline Bad & $2267(39 \%)$ & $3396(46 \%)$ & $2912(46 \%)$ & $2854(53 \%)$ \\
\hline Missing (n) & 18 & 21 & 16 & 15 \\
\hline Restorative sleep (yes) & $3680(63 \%)$ & $4299(58 \%)$ & $3262(52 \%)$ & $2565(48 \%)$ \\
\hline Missing (n) & 18 & 22 & 16 & 16 \\
\hline \multicolumn{5}{|l|}{ Incomet } \\
\hline First quartile ( $\leq 85200$ SEK) & $1446(25 \%)$ & $2085(28 \%)$ & $1262(20 \%)$ & $1478(27 \%)$ \\
\hline Second quartile (85 300 to 111500 SEK) & $1444(24 \%)$ & $1954(27 \%)$ & $1459(23 \%)$ & $1399(26 \%)$ \\
\hline Third quartile (111 600 to 142400 SEK) & $1335(23 \%)$ & $1936(26 \%)$ & $1537(24 \%)$ & $1442(27 \%)$ \\
\hline Fourth quartile ( $\geq 142500$ SEK) & $1655(28 \%)$ & $1425(19 \%)$ & $2075(33 \%)$ & $1089(20 \%)$ \\
\hline Missing (n) & 2 & 2 & 1 & 3 \\
\hline White-collar profession & $4037(76 \%)$ & $3606(53 \%)$ & $4805(82 \%)$ & $2613(53 \%)$ \\
\hline Missing (n) & 548 & 655 & 489 & 490 \\
\hline
\end{tabular}


Results are given as numbers (\%) for categorical variables and as median (IQR) for continuous variables.

*Sex-specific tertiles of total physical activity MET*hours/day. MET, Metabolic Equivalent for Task; F, females; M, males.

†Yearly disposable income (after taxes) split between family members. The information was retrieved from the Longitudinal Integrated Database for Health Insurance and Labour Market Studies database in 1997.

$0-4)$ are those involved in professions requiring university or higher education; blue-collar workers (SSYK: 5-9) include occupations that do not require a special training. Information on occupational level was available from the LISA database from 2001. ${ }^{31}$

In a sensitivity analysis, we further adjusted all statistical models for occupational titles and, as most infections have short incubation periods, we replicated all the analyses using traditional Cox models where time-to-first-event was of interest. Finally, due to the presence of missing values on the covariates included in the models, we carried out multiple imputation using the Multiple Imputation by Chained Equations algorithm assuming a missing at random mechanism. Twenty imputed datasets were thus created and analysed. Statistical analyses were conducted using Stata V.15.1 (Stata Corporation).

\section{RESULTS}

Baseline characteristics of the cohort are shown in table 1 and online supplementary table S2. Participants with high strain jobs had a higher level of total physical activity, were on average less educated, more likely to be shift workers and reported more frequently a short sleep compared with the other groups. Participants in the active job category were more likely to have a postgraduate education and a white-collar profession. Participants with low strain jobs were more likely to sleep longer and have a restorative, good quality sleep.

During a median follow-up time of 16.2 years, we identified a total of 8257 infections requiring healthcare contact. Among the $4577(18 \%)$ participants with at least one infection, the mean number of infections was 1.8 .

In tables 2-4, we report the adjusted HRs and 95\% CI for the association between stress at work (job demand, job control and job strain scores, respectively) and risk of infections. We found a similar monotonic association between job demand and infections in the fully adjusted models (including both confounders and mediators) and in the models without adjustments for potential mediators, with the highest risk in individuals having the highest job demand score. To exemplify, the incidence of infections among individuals in the third tertile of job demand score was $13 \%$ higher $(\mathrm{HR}=1.13 ; 95 \% \mathrm{CI}=1.03$ to 1.24 ) (without mediators: $\mathrm{HR}=1.12 ; 95 \% \mathrm{CI}=1.03$ to 1.22 ) compared with individuals in the first tertile of job demand (table 2). An increased incidence of upper respiratory tract infections ( $\mathrm{HR}=1.15 ; 95 \% \mathrm{CI}=1.00$ to 1.33 ) (without mediators: $\mathrm{HR}=1.18 ; 95 \% \mathrm{CI}=1.03$ to 1.35$)$ and urinary tract infections $(\mathrm{HR}=1.31 ; 95 \% \mathrm{CI}=1.09$ to 1.57$)$ (without mediators: $\mathrm{HR}=1.33 ; 95 \% \mathrm{CI}=1.12$ to 1.58 ) was found in individuals in the highest tertile of job demand compared with individuals in the first tertile, whereas we failed to reject the null hypothesis of no association between job demand and lower respiratory tract, gastrointestinal tract and skin infections.

When comparing the third (highest control) and first tertile of job control in the fully adjusted model, we found no association between decision latitude and infections $(\mathrm{HR}=1.02$; $95 \% \mathrm{CI}=0.92$ to 1.13 ). The same conclusion was obtained when looking at each infection subgroup or when excluding the intermediate variables from the adjustment set (table 3 ). When job strain was modelled as categorical, having low strain as the reference, we found no evidence for an association between passive jobs $(\mathrm{HR}=1.02 ; 95 \% \mathrm{CI}=0.92$ to 1.14$)$ or high strain jobs $(\mathrm{HR}=1.08 ; 95 \% \mathrm{CI}=0.97$ to 1.21$)$ and infections overall (table 4). Contrarily, individuals with active jobs $(\mathrm{HR}=1.10$; $95 \% \mathrm{CI}=1.00$ to 1.22 ) had a $10 \%$ higher incidence of infections compared with individuals with a low strain job. Particularly, having an active job was associated with an increased incidence of upper respiratory tract infections $(\mathrm{HR}=1.24 ; 95 \% \mathrm{CI}=1.06$ to 1.46$)$ and urinary tract infections $(\mathrm{HR}=1.25 ; 95 \% \mathrm{CI}=1.02$ to 1.54$)$. Finally, individuals with high strain jobs showed an increased risk of upper respiratory tract infections $(\mathrm{HR}=1.18$; $95 \% \mathrm{CI}=1.00$ to 1.39 ) compared with individuals with low strain jobs.

Figure 1 shows HRs and 95\% CI for infections occurrence for white-collar and blue-collar workers according to tertiles of job demand and job control scores. For white-collar workers, we observed higher hazards of infections in the third tertile of job demand compared with the first $(\mathrm{HR}=1.17 ; 95 \% \mathrm{CI}=1.05$ to 1.31). For blue-collar workers, we found HR estimates close to unity when comparing the third and first tertiles $(\mathrm{HR}=1.04$; $95 \% \mathrm{CI}=0.87$ to 1.23 ). Tertiles of job demand score, however, are not equally distributed within the two groups defined by occupational type: $29 \%$ of blue-collar workers are in the highest tertile of job demand, versus $35 \%$ of white-collar workers. The distribution of job demand score stratified by occupational type shows that white-collar workers have on average higher demands than blue-collar workers (online supplementary figure S2). Job control dimension was not associated with infection occurrence in any of the subgroups investigated.

When further adjusting our analyses by occupational titles, we found similar results as in the main analyses, with even stronger association between job stress and urinary tract infections (online supplementary tables S3-S5). When we restricted our attention to time-to-first infection, the results on job demands were consistent with the main analyses: we found a higher incidence of infections in individuals exposed to high job demands (third tertile) compared with individuals in the first tertile of the score $(\mathrm{HR}=1.10 ; 95 \% \mathrm{CI}=1.02$ to 1.18 ) (online supplementary table S6). In subgroups analyses, only urinary tract infections retained statistical significance; however, the estimates for upper respiratory tract infections were comparable with the ones in the recurrent event analyses and CIs a bit wider due to a lower number of cases. We found no association between job control dimension and any of the infections investigated (online supplementary table S7); nevertheless, it turned out that a higher job control was associated with an increased risk of infections overall. Finally, when combining job control and job demand within the job strain scale, we did not find any association between active jobs or high strain jobs and infections (online supplementary table S8), contrarily to what was found in a recurrent event analysis. Performing multiple imputations on missing covariates did not alter the results. The estimates found with the imputed data are comparable with those from the main analyses with narrower CIs (online supplementary tables S9-S11). 
Table 2 Adjusted HRs and 95\% Cls for the association between stress at work (measured through the job demand score) and infections requiring healthcare contact (either inpatient or outpatient care) among employed individuals in the Swedish National March Cohort

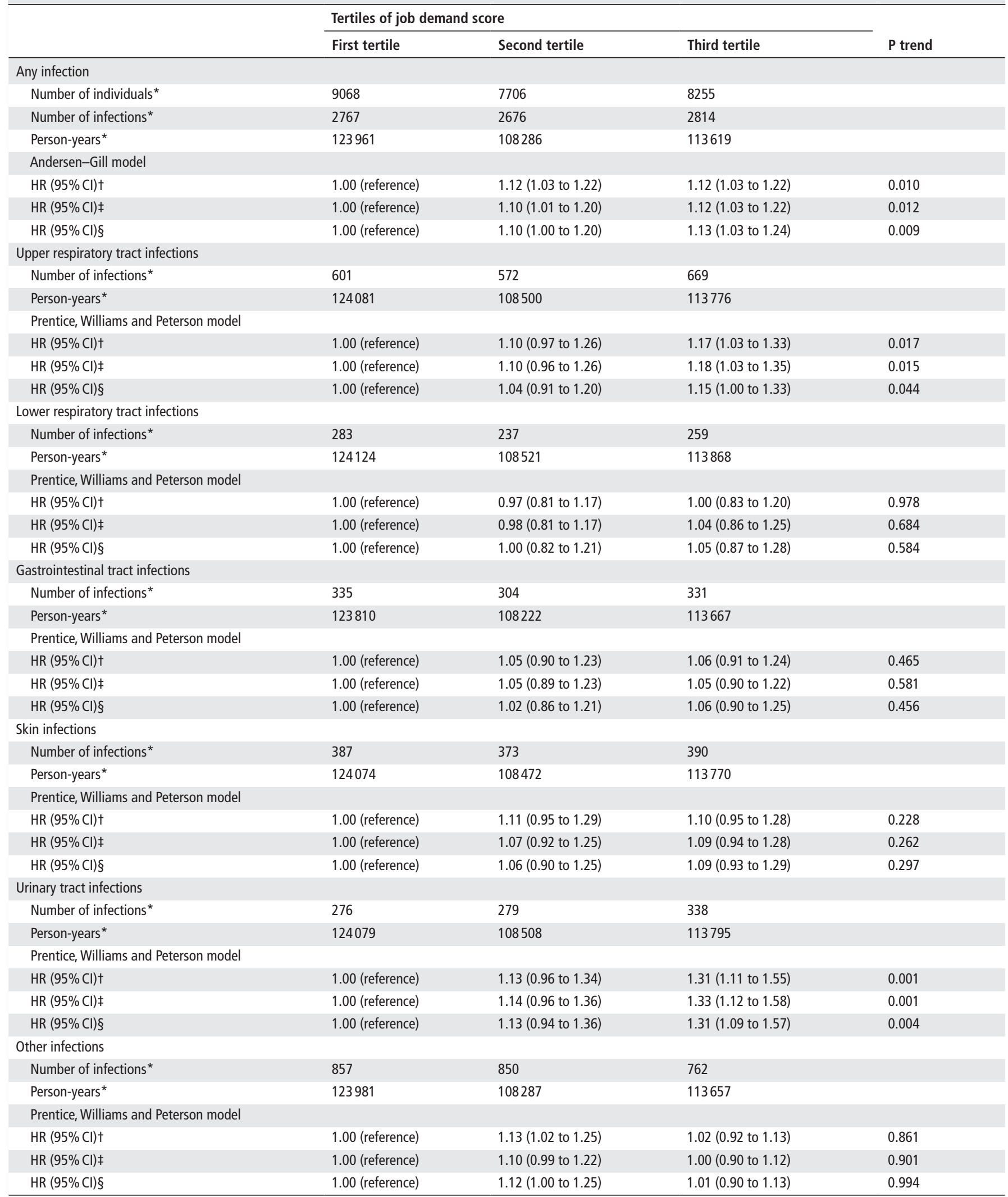

Analyses are conducted using survival models for recurrent events.

*Numbers refer to observations included in the age-adjusted and sex-adjusted models.

†Adjusted by age and sex. $\mathrm{N}=25029$.

¥Adjusted by age, sex, education, physical activity, shift work, Charlson's index and income. $\mathrm{N}=24379$.

$\S$ Adjusted by age, sex, education, physical activity, shift work, Charlson's index, income, smoking status, body mass index, alcohol and sleep duration. $\mathrm{N}=21647$. 
Table 3 Adjusted HRs and 95\% Cls for the association between stress at work (measured through the job control score) and infections requiring healthcare contact (either inpatient or outpatient care) among employed individuals in the Swedish National March Cohort

\begin{tabular}{|c|c|c|c|c|}
\hline & \multicolumn{3}{|c|}{ Tertiles of job control score } & \multirow[b]{2}{*}{$P$ trend } \\
\hline & First tertile & Second tertile & Third tertile & \\
\hline \multicolumn{5}{|l|}{ Any infection } \\
\hline Number of individuals* & 10004 & 8544 & 6481 & \\
\hline Number of infections* & 3324 & 2740 & 2193 & \\
\hline Person-years* & 138710 & 116403 & 90752 & \\
\hline \multicolumn{5}{|l|}{ Andersen-Gill model } \\
\hline $\mathrm{HR}(95 \% \mathrm{Cl}) \dagger$ & 1.00 (reference) & 0.99 (0.91 to 1.07$)$ & $1.02(0.93$ to 1.10$)$ & 0.802 \\
\hline $\mathrm{HR}(95 \% \mathrm{Cl}) \neq$ & 1.00 (reference) & 0.99 (0.91 to 1.08$)$ & 1.02 (0.93 to 1.12$)$ & 0.685 \\
\hline $\mathrm{HR}(95 \% \mathrm{Cl}) \S$ & 1.00 (reference) & 0.99 (0.91 to 1.09$)$ & $1.02(0.92$ to 1.13$)$ & 0.755 \\
\hline \multicolumn{5}{|c|}{ Upper respiratory tract infections } \\
\hline Number of infections* & 760 & 588 & 494 & \\
\hline Person-years* & 138940 & 116566 & 90851 & \\
\hline \multicolumn{5}{|c|}{ Prentice, Williams and Peterson model } \\
\hline $\mathrm{HR}(95 \% \mathrm{Cl}) \dagger$ & 1.00 (reference) & 0.95 (0.84 to 1.07$)$ & 1.01 (0.88 to 1.15$)$ & 0.966 \\
\hline $\mathrm{HR}(95 \% \mathrm{Cl}) \ddagger$ & 1.00 (reference) & 0.94 (0.83 to 1.07 ) & $1.00(0.87$ to 1.16$)$ & 0.900 \\
\hline $\mathrm{HR}(95 \% \mathrm{Cl}) \S$ & 1.00 (reference) & 0.92 (0.80 to 1.05$)$ & 0.99 (0.86 to 1.15$)$ & 0.728 \\
\hline \multicolumn{5}{|c|}{ Lower respiratory tract infections } \\
\hline Number of infections* & 321 & 246 & 212 & \\
\hline Person-years* & 139022 & 116601 & 90892 & \\
\hline \multicolumn{5}{|c|}{ Prentice, Williams and Peterson model } \\
\hline $\mathrm{HR}(95 \% \mathrm{Cl}) \dagger$ & 1.00 (reference) & $0.92(0.77$ to 1.10$)$ & 0.97 (0.81 to 1.16$)$ & 0.619 \\
\hline $\mathrm{HR}(95 \% \mathrm{Cl}) \neq$ & 1.00 (reference) & 0.94 (0.78 to 1.14 ) & 1.00 (0.81 to 1.23$)$ & 0.918 \\
\hline $\mathrm{HR}(95 \% \mathrm{Cl}) \S$ & 1.00 (reference) & $0.98(0.80$ to 1.20$)$ & 1.05 (0.84 to 1.31$)$ & 0.749 \\
\hline \multicolumn{5}{|c|}{ Gastrointestinal tract infections } \\
\hline Number of infections* & 377 & 320 & 273 & \\
\hline Person-years* & 138741 & 116305 & 90654 & \\
\hline \multicolumn{5}{|c|}{ Prentice, Williams and Peterson model } \\
\hline HR $(95 \% \mathrm{Cl}) \dagger$ & 1.00 (reference) & 1.05 (0.90 to 1.22$)$ & $1.13(0.96$ to 1.32$)$ & 0.152 \\
\hline HR $(95 \% \mathrm{Cl}) \ddagger$ & 1.00 (reference) & 1.04 (0.88 to 1.22$)$ & $1.13(0.95$ to 1.34$)$ & 0.200 \\
\hline $\mathrm{HR}(95 \% \mathrm{Cl}) \S$ & 1.00 (reference) & 1.04 (0.88 to 1.24$)$ & 1.10 (0.92 to 1.33$)$ & 0.300 \\
\hline \multicolumn{5}{|l|}{ Skin infections } \\
\hline Number of infections* & 462 & 379 & 309 & \\
\hline Person-years* & 138961 & 116510 & 90845 & \\
\hline \multicolumn{5}{|c|}{ Prentice, Williams and Peterson model } \\
\hline $\mathrm{HR}(95 \% \mathrm{Cl}) \dagger$ & 1.00 (reference) & 0.97 (0.83 to 1.13$)$ & 0.97 (0.83 to 1.14$)$ & 0.689 \\
\hline $\mathrm{HR}(95 \% \mathrm{Cl}) \neq$ & 1.00 (reference) & $0.97(0.83$ to 1.13$)$ & $0.98(0.83$ to 1.16$)$ & 0.783 \\
\hline $\mathrm{HR}(95 \% \mathrm{Cl}) \S$ & 1.00 (reference) & 0.95 (0.80 to 1.12 ) & 0.98 (0.82 to 1.17$)$ & 0.733 \\
\hline \multicolumn{5}{|l|}{ Urinary tract infections } \\
\hline Number of infections* & 347 & 329 & 217 & \\
\hline Person-years* & 138964 & 116522 & 90895 & \\
\hline \multicolumn{5}{|c|}{ Prentice, Williams and Peterson model } \\
\hline $\mathrm{HR}(95 \% \mathrm{Cl}) \dagger$ & 1.00 (reference) & 1.14 (0.98 to 1.34 ) & $0.98(0.82$ to 1.16$)$ & 0.873 \\
\hline $\mathrm{HR}(95 \% \mathrm{Cl}) \ddagger$ & 1.00 (reference) & 1.14 (0.97 to 1.35$)$ & $0.97(0.81$ to 1.17$)$ & 0.918 \\
\hline HR $(95 \% \mathrm{Cl}) \S$ & 1.00 (reference) & $1.16(0.97$ to 1.39$)$ & 0.95 (0.77 to 1.17$)$ & 0.938 \\
\hline \multicolumn{5}{|l|}{ Other infections } \\
\hline Number of infections* & 1007 & 813 & 649 & \\
\hline Person-years* & 138763 & 116415 & 90747 & \\
\hline \multicolumn{5}{|c|}{ Prentice, Williams and Peterson model } \\
\hline $\mathrm{HR}(95 \% \mathrm{Cl}) \dagger$ & 1.00 (reference) & 0.99 (0.89 to 1.09$)$ & 0.99 (0.89 to 1.10$)$ & 0.840 \\
\hline $\mathrm{HR}(95 \% \mathrm{Cl}) \neq$ & 1.00 (reference) & 0.97 (0.87 to 1.07 ) & 0.96 (0.86 to 1.08$)$ & 0.500 \\
\hline HR $(95 \% \mathrm{Cl}) \S$ & 1.00 (reference) & 0.96 (0.86 to 1.07 ) & $0.96(0.85$ to 1.09$)$ & 0.487 \\
\hline
\end{tabular}

Analyses are conducted using survival models for recurrent events.

${ }^{*}$ Numbers refer to observations included in the age-adjusted and sex-adjusted models.

†Adjusted by age and sex. $\mathrm{N}=25029$.

¥Adjusted by age, sex, education, physical activity, shift work, Charlson's index and income. N=24379.

$\S$ Adjusted by age, sex, education, physical activity, shift work, Charlson's index, income, smoking status, body mass index, alcohol and sleep duration. $\mathrm{N}=21647$. 
Table 4 Adjusted HRs and 95\% Cls for the association between stress at work (measured through the job strain score) and infections requiring healthcare contact (either inpatient or outpatient care) among employed individuals in the Swedish National March Cohort

\begin{tabular}{|c|c|c|c|c|}
\hline \multirow{3}{*}{ Any infection } & \multicolumn{4}{|l|}{ Job strain } \\
\hline & \multirow[t]{2}{*}{ Low strain job } & \multirow[t]{2}{*}{ Passive job } & \multirow[t]{2}{*}{ Active job } & \multirow[t]{2}{*}{ High strain job } \\
\hline & & & & \\
\hline Number of individuals* & 5882 & 7402 & 6334 & 5411 \\
\hline Number of infections* & 1838 & 2391 & 2183 & 1845 \\
\hline Person-years* & 81607 & 101652 & 87660 & 74947 \\
\hline \multicolumn{5}{|l|}{ Andersen-Gill model } \\
\hline $\mathrm{HR}(95 \% \mathrm{Cl}) \dagger$ & 1.00 (reference) & 1.04 (0.94 to 1.14$)$ & 1.11 (1.01 to 1.22$)$ & 1.10 (0.99 to 1.21 ) \\
\hline $\mathrm{HR}(95 \% \mathrm{Cl}) \neq$ & 1.00 (reference) & 1.03 (0.93 to 1.14$)$ & 1.10 (1.00 to 1.22$)$ & 1.08 (0.97 to 1.20$)$ \\
\hline $\mathrm{HR}(95 \% \mathrm{Cl}) \S$ & 1.00 (reference) & 1.02 (0.92 to 1.14$)$ & 1.10 (1.00 to 1.22$)$ & 1.08 (0.97 to 1.21$)$ \\
\hline \multicolumn{5}{|c|}{ Upper respiratory tract infections } \\
\hline Number of infections* & 366 & 520 & 522 & 434 \\
\hline Person-years* & 81718 & 101798 & 87772 & 75069 \\
\hline \multicolumn{5}{|c|}{ Prentice, Williams and Peterson model } \\
\hline $\mathrm{HR}(95 \% \mathrm{Cl}) \dagger$ & 1.00 (reference) & 1.09 (0.94 to 1.27$)$ & 1.26 (1.08 to 1.46$)$ & 1.18 (1.02 to 1.37$)$ \\
\hline $\mathrm{HR}(95 \% \mathrm{Cl}) \ddagger$ & 1.00 (reference) & $1.10(0.94$ to 1.28$)$ & 1.26 (1.08 to 1.46$)$ & 1.19 (1.01 to 1.39$)$ \\
\hline HR $(95 \% \mathrm{Cl}) \S$ & 1.00 (reference) & $1.10(0.93$ to 1.29$)$ & 1.24 (1.06 to 1.46$)$ & 1.18 (1.00 to 1.39$)$ \\
\hline \multicolumn{5}{|c|}{ Lower respiratory tract infections } \\
\hline Number of infections* & 180 & 226 & 196 & 177 \\
\hline Person-years* & 81730 & 101837 & 87828 & 75119 \\
\hline \multicolumn{5}{|c|}{ Prentice, Williams and Peterson model } \\
\hline $\mathrm{HR}(95 \% \mathrm{Cl}) \dagger$ & 1.00 (reference) & $1.00(0.81$ to 1.23$)$ & 1.00 (0.81 to 1.24$)$ & 1.08 (0.86 to 1.36$)$ \\
\hline $\mathrm{HR}(95 \% \mathrm{Cl}) \neq$ & 1.00 (reference) & 0.99 (0.79 to 1.24$)$ & 1.04 (0.84 to 1.28$)$ & 1.07 (0.84 to 1.37$)$ \\
\hline HR $(95 \% \mathrm{Cl}) \S$ & 1.00 (reference) & 0.89 (0.70 to 1.14$)$ & $1.00(0.80$ to 1.26$)$ & 1.04 (0.81 to 1.35 ) \\
\hline \multicolumn{5}{|c|}{ Gastrointestinal tract infections } \\
\hline Number of infections* & 239 & 284 & 241 & 206 \\
\hline Person-years* & 81475 & 101607 & 87647 & 74972 \\
\hline \multicolumn{5}{|c|}{ Prentice, Williams and Peterson model } \\
\hline $\mathrm{HR}(95 \% \mathrm{Cl}) \dagger$ & 1.00 (reference) & 0.94 (0.79 to 1.12$)$ & 0.95 (0.79 to 1.13$)$ & 0.91 (0.75 to 1.10$)$ \\
\hline $\mathrm{HR}(95 \% \mathrm{Cl}) \neq$ & 1.00 (reference) & 0.95 (0.79 to 1.14$)$ & 0.93 (0.78 to 1.12$)$ & 0.91 (0.74 to 1.11 ) \\
\hline HR $(95 \% \mathrm{Cl}) \S$ & 1.00 (reference) & $0.95(0.78$ to 1.16$)$ & $0.91(0.75$ to 1.10$)$ & 0.88 (0.71 to 1.09$)$ \\
\hline \multicolumn{5}{|l|}{ Skin infections } \\
\hline Number of infections* & 249 & 362 & 302 & 237 \\
\hline Person-years* & 81689 & 101807 & 87755 & 75065 \\
\hline \multicolumn{5}{|c|}{ Prentice, Williams and Peterson model } \\
\hline $\mathrm{HR}(95 \% \mathrm{Cl}) \dagger$ & 1.00 (reference) & 1.13 (0.95 to 1.34$)$ & $1.10(0.92$ to 1.31$)$ & 1.07 (0.88 to 1.30$)$ \\
\hline $\mathrm{HR}(95 \% \mathrm{Cl}) \neq$ & 1.00 (reference) & 1.15 (0.97 to 1.38$)$ & 1.11 (0.93 to 1.33$)$ & 1.07 (0.87 to 1.32 ) \\
\hline $\mathrm{HR}(95 \% \mathrm{Cl}) \S$ & 1.00 (reference) & 1.12 (0.92 to 1.35$)$ & 1.08 (0.89 to 1.30$)$ & 1.11 (0.89 to 1.38$)$ \\
\hline \multicolumn{5}{|l|}{ Urinary tract infections } \\
\hline Number of infections* & 185 & 243 & 262 & 203 \\
\hline Person-years* & 81719 & 101807 & 87782 & 75073 \\
\hline \multicolumn{5}{|c|}{ Prentice, Williams and Peterson model } \\
\hline $\mathrm{HR}(95 \% \mathrm{Cl}) \dagger$ & 1.00 (reference) & 1.04 (0.86 to 1.27$)$ & 1.29 (1.06 to 1.55$)$ & 1.16 (0.94 to 1.42$)$ \\
\hline $\mathrm{HR}(95 \% \mathrm{Cl}) \ddagger$ & 1.00 (reference) & $1.03(0.85$ to 1.26$)$ & 1.29 (1.07 to 1.57$)$ & 1.16 (0.93 to 1.43$)$ \\
\hline HR $(95 \% \mathrm{Cl}) \S$ & 1.00 (reference) & 1.02 (0.82 to 1.27$)$ & 1.25 (1.02 to 1.54$)$ & 1.11 (0.88 to 1.41 ) \\
\hline \multicolumn{5}{|l|}{ Other infections } \\
\hline Number of infections* & 591 & 734 & 596 & 548 \\
\hline Person-years* & 81593 & 101702 & 87654 & 74975 \\
\hline \multicolumn{5}{|c|}{ Prentice, Williams and Peterson model } \\
\hline $\mathrm{HR}(95 \% \mathrm{Cl}) \dagger$ & 1.00 (reference) & $0.98(0.88$ to 1.10$)$ & 0.98 (0.87 to 1.10$)$ & 1.01 (0.89 to 1.15 ) \\
\hline HR $(95 \% \mathrm{Cl}) \neq$ & 1.00 (reference) & 1.01 (0.90 to 1.15$)$ & 0.96 (0.85 to 1.08$)$ & 1.02 (0.90 to 1.17$)$ \\
\hline HR $(95 \% \mathrm{Cl}) \S$ & 1.00 (reference) & 1.03 (0.90 to 1.17$)$ & 0.98 (0.86 to 1.12$)$ & 1.03 (0.89 to 1.19$)$ \\
\hline
\end{tabular}

Analyses are conducted using survival models for recurrent events.

*Numbers refer to observations included in the age-adjusted and sex-adjusted models.

†Adjusted by age and sex. $\mathrm{N}=25029$.

¥Adjusted by age, sex, education, physical activity, shift work, Charlson's index and income. $\mathrm{N}=24379$.

$\S$ Adjusted by age, sex, education, physical activity, shift work, Charlson's index, income, smoking status, body mass index, alcohol and sleep duration. $\mathrm{N}=21647$. 


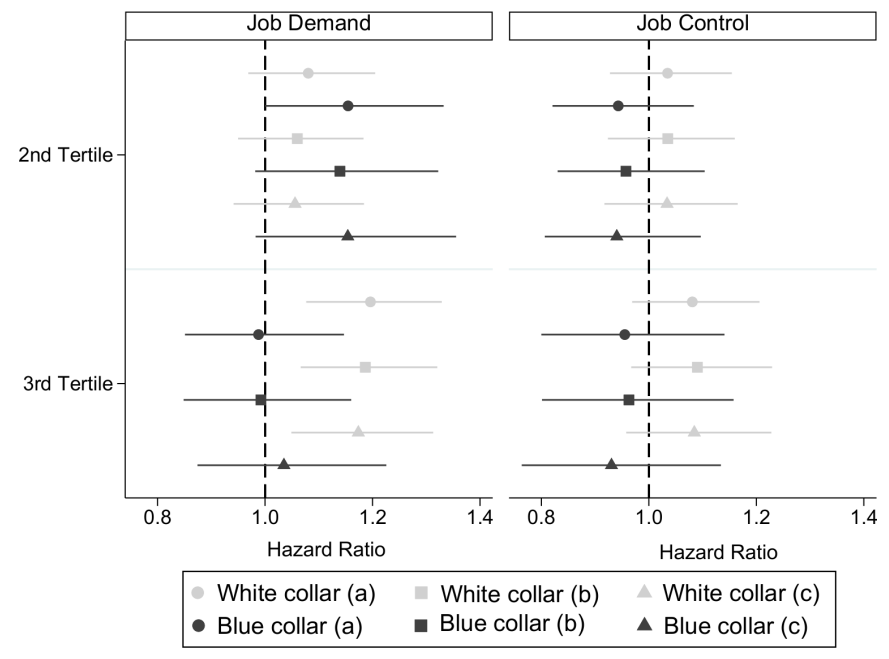

Figure 1 Adjusted HRs and 95\% Cls for the association between job stress (job demand and job control scores—-first tertile taken as the reference) and infections requiring healthcare contact (either inpatient or outpatient care) among employed individuals in the Swedish National March Cohort. Analyses are performed using the Andersen-Gill model and stratified by white and blue collars. (a) Adjusted by age and sex. (b) Adjusted by age, sex, education, physical activity, shift work, Charlson's index and income. (c) Adjusted by age, sex, education, physical activity, shift work, Charlson's index, income, smoking status, body mass index, alcohol and sleep duration.

\section{DISCUSSION}

We found that employees reporting high job demands have a higher risk of infections, specifically upper respiratory tract infections and urinary tract infections, than those reporting a lower level of demands at work. This result is in line with the hypothesis that work stress due to high psychological job demands might be involved in the pathogenesis of infections. Our findings also suggest that the decision latitude at work is unlikely to increase risk for infections leading to hospital contact. As for job strain, active jobs were associated with an increased incidence of infections compared with low strain jobs. No difference was observed in high strain jobs compared with low strain jobs.

To our knowledge, this is the first large prospective cohort study investigating the association between stress at work and a wide range of objectively assessed infections. The association we found between job demands and upper respiratory tract infections is consistent with one cross-sectional study ${ }^{16}$ and one prospective study with self-reported outcome. ${ }^{18}$ It is likely that when job demands are perceived to go beyond our capacity to cope, we experience a hormonal response that alters the immune function. ${ }^{9}$

With regard to infections of the urinary tract, we are not aware of studies that investigated the association with job stress, but a recent review pointed out possible connections between stress and lower urinary tract symptoms, ${ }^{32}$ concluding that stress and urologic conditions might have common neuropharmacological pathways. It is plausible that individuals that cannot cope with the high amount of demands during their work day feel that the time at their disposal is not enough to carry out their assignments. They are therefore more likely to hold urine for longer length of time, which itself increases the risk of infections. Despite the association found in our study seems to be relatively strong, we cannot exclude the possibility of a chance finding and it needs to be replicated in future studies before providing a causal interpretation. It is also likely that it is not stress per se which causes urinary infections, but a series of cascade reactions caused by stress which impair the immune system.

Contrarily to our hypothesis, job control dimension did not seem an important factor in determining infection occurrence. Our results contrast with two studies that found an increase in respiratory infections in workers with low job control. ${ }^{17}{ }^{18}$ In addition, in a time-to-first infection analysis, our results suggested that high—and not low—control at work was associated with higher incidence of infections, but this was not confirmed in a recurrent event analysis and it might be due to chance.

Our findings do not support the hypothesis that high strain jobs are associated with higher incidence of infections, while we found some evidence that having an active job increases risk of infections in agreement with previous research. ${ }^{33}$ Even if high control at work often is considered to attenuate a detrimental influence of high demands, active jobs and high strain jobs might measure different aspects of occupational stress. The former captures stress derived from managerial situations with high level responsibilities and many decisions to take, while the latter captures stress related to routine work. Nevertheless, cautiousness is needed here. Point estimates for the association between high strain jobs and infections are very similar and CIs highly overlapping to those referring to active jobs. It is also worth noticing that high job strain was the least common category in our cohort.

Finally, when we stratified our analyses on type of occupation, increased occurrence of infections was observed in white collars, but not blue collars, with high job demands. Nonetheless, we should be cautious with this interpretation as it might be due to an insufficient power of the study to detect the association in blue-collar workers given their smaller sample size. In addition, data on occupational type are available only starting from 2001. For example, individuals retired, emigrated or who died during the first 4 years of follow-up are not included in this subgroup analysis. It is reasonable that different types of jobs with similar scores in job demand scale involve completely different tasks, which might have different responses on infection occurrence; on the contrary, the increased incidence of infections among white-collar workers may be due to higher demand values experienced by white collars, ${ }^{34}$ which further strengthens the argument for a link between job demands and infections occurrence.

Strengths of our study include the prospective design, the complete long-term follow-up, the large cohort of employed individuals, the wide range of confounders controlled for in the analyses and the objective assessment of infections. Also, the analysis of type-specific infections is necessary to extend the current knowledge on the association between job stress and infections, and the censoring of individuals at their retirement consented to avoid cumulating person-year at risk when occupational stress is not expected to be relevant anymore. In addition, the use of statistical models for recurrent events allowed us to consider all infections occurring over follow-up and not limit the analyses to the first infection. Nonetheless, being aware of the short incubation period that most infections have, we have also conducted analyses where the focus was on time-to-first infection and compared results with the main analysis.

The decision latitude and the job demand dimensions are often combined, which precludes disentangling their individual effects. Because we considered job demands and decision latitude as separate dimensions, it was possible to infer the importance of work demands itself after investigating which aspect of work stress that was associated with infections. Finally, knowing that alcohol consumption, smoking, BMI and sleep duration 
could reasonably be on the causal pathway between job stress and infections, ${ }^{35}$ we conducted the analyses with both models, adjusted and non-adjusted for these factors, and we found that the results were almost unchanged.

Among limitations of our study, job strain was self-reported and assessed only at baseline. This might inaccurately reflect job strain during the entire follow-up. Individuals exposed to high levels of job strain are more likely to turn into jobs requiring less strain than the opposite, and this should happen independently of the outcome with subsequent underestimation of the association of interest. ${ }^{36}$ However, a high proportion of participants $(39 \%)$ recruited were 50 years or older and likely to retire during follow-up. Because of the availability of the information on retirement from LISA database, we limited the bias censoring participants at their retirement date. In addition, other occupational characteristics such as working hours or sector of industry might have confounded our estimates, but we did not have enough information to control the analyses for these variables.

One should also keep in mind that primary care (contacts with general practitioners) is yet not recorded in the National Patient Register and that we could not capture infections treated in outpatient care before 2001 (when the outpatient register was established). As a result, we might have underestimated any true association between occupational stress and minor infections. In addition, we presented analyses for specific subgroups of infections but we could not differentiate between infectious agents; therefore, we had to suppose that the association between job stress and infections is similar, regardless of pathogen.

We conclude that overall, our study provides evidence that stressful jobs are unlikely to substantially increase the risk of infections requiring medical attention. However, occupational stress as assessed as high job demands might increase the risk of such infections, in particular upper respiratory tract infections and urinary tract infections. Since causal inference is hampered by the weak associations and possible influence of residual confounding, our findings need confirmation in other-ideally large and prospective-studies.

Contributors FG analysed the data, wrote the first draft of the paper and edited the paper according to co-authors' suggestions. RB contributed to the statistical analyses and critically revised the paper. H-OA made substantial contributions to data and funding acquisition and provided critical feedbacks to the paper. TA helped with the interpretation of the results and contributed to the writing of the paper. YTL supervised the project and contributed to the final version of the paper.

Funding This work was supported by ICA AB; Telefonaktiebolaget LM Ericsson; the Swedish Cancer Society (Grant CAN 2012/591) and a Karolinska Institutet Distinguished Professor Award (2368/10-221).

Competing interests None declared.

Patient consent for publication Not required.

Ethics approval The study was approved by the Regional Ethical Review Board at Karolinska Institutet and all participants provided informed consent.

Provenance and peer review Not commissioned; externally peer reviewed.

Data availability statement Data may be obtained from a third party and are not publicly available. Researchers can obtain access to data by contacting the Swedish National March Cohort steering committee (https://ki.se/en/meb/theswedish-national-march-cohort-nmc). To gain access, data requestors will need to sign a data access agreement.

\section{ORCID iDs}

Francesca Ghilotti http://orcid.org/0000-0002-7978-376X

Torbjörn Åkerstedt http://orcid.org/0000-0001-8049-8504

\section{REFERENCES}

1 Hemingway $\mathrm{H}$, Marmot M. Evidence based cardiology: psychosocial factors in the aetiology and prognosis of coronary heart disease. systematic review of prospective cohort studies. BMJ 1999;318:1460-7.
2 Kivimäki M, Steptoe A. Effects of stress on the development and progression of cardiovascular disease. Nat Rev Cardiol 2018;15:215-29.

3 Madsen IEH, Nyberg ST, Magnusson Hanson LL, et al. Job strain as a risk factor for clinical depression: systematic review and meta-analysis with additional individual participant data. Psychol Med 2017;47:1342-56.

4 Stansfeld S, Candy B. Psychosocial work environment and mental health--a metaanalytic review. Scand J Work Environ Health 2006;32:443-62.

5 Cohen S, Williamson GM. Stress and infectious disease in humans. Psychol Bull 1991;109:5-24.

6 Falagas ME, Karamanidou C, Kastoris AC, et al. Psychosocial factors and susceptibility to or outcome of acute respiratory tract infections. Int I Tuberc Lung Dis 2010:14:141-8.

7 Pedersen A, Zachariae R, Bovbjerg DH. Influence of psychological stress on upper respiratory infection--a meta-analysis of prospective studies. Psychosom Med 2010;72:823-32

8 Padgett DA, Glaser R. How stress influences the immune response. Trends Immunol 2003;24:444-8.

9 Cohen S. Psychological stress, immunity, and upper respiratory infections. Curr Dir Psychol Sci 1996;5:86-9.

10 Eurofound. Sixth European working conditions survey - overview report (2017 update). Luxembourg, 2017

11 Hassard J, Teoh KRH, Visockaite G, et al. The cost of work-related stress to society: a systematic review. J Occup Health Psychol 2018;23:1-17.

12 Morikawa Y, Kitaoka-Higashiguchi K, Tanimoto C, et al. A cross-sectional study on the relationship of job stress with natural killer cell activity and natural killer cell subsets among healthy nurses. J Occup Health 2005;47:378-83.

13 Boscolo P, Di Donato A, Di Giampaolo L, et al. Blood natural killer activity is reduced in men with occupational stress and job insecurity working in a university. Int Arch Occup Environ Health 2009:82:787-94.

14 Boscolo P, Forcella L, Reale M, et al. Job strain in different types of employment affects the immune response. Work 2012;41(Suppl 1):2950-4.

15 Clays E, De Bacquer D, Delanghe J, et al. Associations between dimensions of job stress and biomarkers of inflammation and infection. J Occup Environ Med 2005; 47:878-83

16 Mohren DC, Swaen GM, Borm PJ, et al. Psychological job demands as a risk factor for common cold in a Dutch working population. J Psychosom Res 2001:50:21-7.

17 Runeson-Broberg R, Norbäck D. Work-Related psychosocial stress as a risk factor for asthma, allergy, and respiratory infections in the Swedish workforce. Psychol Rep 2014;114:377-89.

18 Park S-G, Kim H-C, Min J-Y, et al. A prospective study of work stressors and the common cold. Occup Med 2011;61:53-6.

19 Trolle Lagerros Y, Hantikainen E, Mariosa D, et al. Cohort profile: the Swedish national March cohort. Int J Epidemiol 2017;46:795-795e.

20 Theorell T, Perski A, Akerstedt T, et al. Changes in job strain in relation to changes in physiological state. A longitudinal study. Scand J Work Environ Health 1988;14:189-96.

21 Karasek R, Choi B, Ostergren P-O, et al. Testing two methods to create comparable scale scores between the job content questionnaire (JCQ) and JCQ-like questionnaires in the European JACE study. Int J Behav Med 2007;14:189-201.

22 Fransson El, Nyberg ST, Heikkilä K, et al. Comparison of alternative versions of the job demand-control scales in 17 European cohort studies: the IPD-Work Consortium. BMC Public Health 2012:12:62.

23 Ludvigsson JF, Andersson E, Ekbom A, et al. External review and validation of the Swedish national inpatient register. BMC Public Health 2011;11:450.

24 Amorim LDAF, Cai J. Modelling recurrent events: a tutorial for analysis in epidemiology. Int J Epidemiol 2015;44:324-33.

25 Andersen PK, Gill RD. Cox's regression model for counting processes: a large sample study. Ann Stats 1982;10:1100-20.

26 Prentice RL, Williams BJ, Peterson AV. On the regression analysis of multivariate failure time data. Biometrika 1981;68:373-9.

27 Kelly PJ, Lim LL. Survival analysis for recurrent event data: an application to childhood infectious diseases. Stat Med 2000;19:13-33.

28 Textor J, Hardt J, Knüppel S. DAGitty: a graphical tool for analyzing causal diagrams. Epidemiology 2011;22:745.

29 Ainsworth BE, Haskell WL, Leon AS, et al. Compendium of physical activities: classification of energy costs of human physical activities. Med Sci Sports Exerc 1993:25:71-80.

30 Charlson ME, Pompei P, Ales KL, et al. A new method of classifying prognostic comorbidity in longitudinal studies: development and validation. J Chronic Dis 1987;40:373-83.

31 Ludvigsson JF, Svedberg P, Olén O, et al. The longitudinal integrated database for health insurance and labour market studies (LISA) and its use in medical research. Eur J Epidemiol 2019;34:423-37.

32 Sanford MT, Rodriguez LV. The role of environmental stress on lower urinary tract symptoms. Curr Opin Urol 2017;27:268-73. 
33 Heikkilä K, Madsen IEH, Nyberg ST, et al. Job strain and the risk of severe asthma exacerbations: a meta-analysis of individual-participant data from 100000 European men and women. Allergy 2014;69:775-83.

34 Åkerstedt T, Discacciati A, Häbel H, et al. Psychosocial work demands and physical workload decrease with ageing in blue-collar and white-collar workers: a prospective study based on the SLOSH cohort. BMJ Open 2019;9:e030918.
35 Heikkilä K, Fransson El, Nyberg ST, et al. Job strain and health-related lifestyle: findings from an individual-participant meta-analysis of 118,000 working adults. Am J Public Health 2013;103:2090-7.

36 Choi BK, Schnall P, Landsbergis P, et al. Recommendations for individual participant data meta-analyses on work stressors and health outcomes: comments on IPD-Work Consortium papers. Scand J Work Environ Health 2015;41:299-311. 